\title{
STUDYING LONG-TERM LARGE-SCALE CHANGE: CONCLUDING REFLECTIONS ON THE RELEVANT UNIT OF ANALYSIS ${ }^{1}$
}

\author{
Timothy Patrick Moran \\ Department of Sociology \\ Stony Brook University, New York \\ tpmoran@notes.cc.sunysb.edu
}

So oft in theologic wars, The disputants, I ween, Rail on in utter ignorance Of what each other mean, And prate about an Elephant

Not one of them has seen!

-- John Godfrey Saxe

"The Blind Men and the Elephant"

When I first received the papers as discussant for the ASA panel, Methodology for WorldSystems Analysis (the papers that would come to constitute this journal's special issue), I didn't quite know how to proceed. In large part, the papers used innovative methodology to answer interesting substantive questions, so quality was not a question. The author's were rigorous in how this methodology was applied, and creative in searching for and manipulating worldwide data, so no need to comment there. The problem was semantic. Not in the "petty dispute over word choice" sense of semantic, but in the ontological relationship between distinctive concepts and their intended (in this case theoretical) meaning.

The motivation for most of the authors in this volume is the extent to which we, as scholars interested in large-scale change, can overcome various methodological problems associated with collecting and analyzing worldwide data, whether quantitative or qualitative in character. Whether we refer to this type of research as "global," "comparative," or by the latest trendy term "transnational," social science is of little semantic (or substantive) consequence. It's all macrosociology in one form or another.

But these motivations are entirely different than methodologically advancement within the theoretical framework that has come to be called "world-systems analysis." While perhaps overlapping, these are not necessarily identical sets of issues. This is not to say that one set of issues is more salient than the other, but it is, I will argue, increasingly important to remember that they are different sets of issues, and the difference is more important than a debate over semantics might suggest. In one of his essays that, when taken together, became the major

\footnotetext{
${ }^{1}$ This essay draws heavily from a forthcoming book, Unveiling Inequality: A World-Historical Perspective, co-authored with Roberto Patricio Korzeniewicz.
}

Copyright $@$ 2009, American Sociological Association, Volume XV, Number 1, Pages 115-123 ISSN 1076-156X 
methodological statements in the world-systems tradition, Terence Hopkins (1982b:149) frames the issue like this:

There is now a growing number of good articles on method which show how...a given method may be made use of in world-systems studies as they understand them. (But a different line of attack is): given the directions that world-system studies are taking, what basic problems of method do they seem to raise? I imagine the two lines of attack will in due course meet and prove complementary, but they are still very far apart now. (Hopkins 1982a:38)

The difference between macro comparative social science in various forms and worldsystems analysis in particular can be illustrated by looking at how each frames relevant questions for analyzing inequality, for example. Scholars of the former are currently asking questions like: why do the countries of Latin America have higher levels of inequality than those in say Western Europe? This directs inquiry inward, toward the nation-states themselves, as in: What are the conditions within the countries of Western Europe in contrast to the countries in Latin America that allow the former to have relatively egalitarian income distributions and the others to not? From a world-system perspective, inequality goes from being a condition to a process, and the questions are restated: How did the countries of Western Europe come to occupy the level of inequality they have in the world and the countries of Latin America the level of inequality they have? More interestingly, are the two related? At fundamental issue is the unit of analysis.

\section{PARTS AND WHOLES IN THEORY AND METHOD}

In the Indian parable "The Blind Men and the Elephant," each man touches a different part of the animal, but only one part. When they then compare notes on what they felt, they learn they are in complete disagreement. Each believes they are describing the whole of the elephant, however in reality they are only describing a part of it, thus while each is "in the right" in what they are explaining, each only has a partial understanding of the overall whole. Conceptualizing the relationship between parts and wholes - that is, specifying the relevant unit if analysis - is the key epistemological innovation that distinguishes world-systems analysis from other forms of macro comparative social science.

While much has been written about determining the proper unit of analysis in social scientific study, let's start with the preposition that at least three criteria are involved, however implicitly to the analyst. First, and primarily, the unit of analysis must have theoretical relevance. As Max Weber (1996 [1905]) argued, choice of the proper unit of analysis should be guided by theoretical criteria, as its boundaries should contain within them all the processes that are relevant for understanding the phenomenon under investigation. Second, the units themselves must exhibit independence from each other. If the unit is not independent of other instances of the processes under investigation, then no new information can be added to test the theory. Third, the units must be neither indivisible nor combinable. If some broader structure is made up of several independent instances of a process, or a process occurs within a space above the level of interest, then the need to divide or combine units could possibly nullify the phenomenon that was under investigation from the start. 


\section{JOURNAL OF WORLD-SYSTEMS RESEARCH}

For the most part, sociology as a social scientific discipline has developed over the last two centuries without much awareness of the fact that different social problems require different units of analysis. Until very recently, the underlying assumption, embedded in the discipline from its onset, is that the nation-state (or national society) constitutes the crucial and only possible unit of analysis. With reference to the criteria above, the overarching assumption is that society takes place within distinct national borders and over their particular geography; inside these boundaries processes are "internal" and outside them processes are "external." Nation-states are assumed to be self-evident and discreet social units, independent and indivisible, and therefore comparable for both theoretical and statistical purposes, as given loci within which social change takes place. In many studies, the choice of nations as the privileged unit of analysis is not even theoretically informed, but often driven by a combination of academic custom and the format in which data are most easily available.

Part and parcel of this uncritical attachment to a notion of society as a discreet, bounded, "national" unit is the fact that we also tend to investigate the happenings in a very small percentage of these units - the most wealthy dozen or so - and then export these observations as if this accurately represents the happenings in all of them, or in "society writ large." In research published in the main journals, for example, it is extremely common to find that studies that draw exclusively on data from the United States (or some combination of the other wealthy nations) seek to make conclusive statements about the universal character of the phenomena they are investigating, with neither a caveat or even acknowledgment of the limited scope of such inquiry. In other words, sociology, but also the contemporary social sciences more broadly, have the curious particularity of claiming to view the world through theoretical perspectives that are purportedly universal, but in fact have been constructed by focusing mainly, in some cases even solely, on the experience of a very small fraction of the world's population. ${ }^{2}$

As an example, take the argument that predominated in sociology, via the leading subfield of stratification and mobility studies, for much of the twentieth century: the development of a more complex division of labor entails a shift from a system of stratification based around ascribed characteristics (one's origin of birth) to one based around achieved characteristics (especially education). Observing processes of social inequality and mobility solely or primarily as they take place within the borders of wealthy countries indeed appears to confirm such a shift, and many studies in the social sciences have been dedicated to documenting, over and over again, such a transition. But the vast majority of these studies draws their observations from a handful of wealthy nations, and deems this to be a sufficient basis to make conclusive statements about social mobility regimes writ large. Such unacknowledged biases are ingrained in the very foundations of much of the social sciences, and continue to permeate the social sciences as they are constructed day to day.

In macro comparative research, then, the tendency is to reify the nation-state, or national societies, as the sole independent unit of analysis. They are independent units whose level of development was determined by the presence or absence of certain conditions. Conceptualized in this way, nation-states are primarily wholes (national societies) that can be combined as parts to form an international system of states, or an international trading regime, and so forth. The simple

\footnotetext{
${ }^{2}$ The population of the richest 22 countries accounts for a little less than 13 percent of the world's total population.
} 
aggregation done in this manner implies that the whole is nothing more than the sum of its parts. Thus, we could translate from the whole to the parts and back again with ease, and therefore no special meaning is given to the social whole (see Bach 1982 for an extended discussion of this point).

For much of the twentieth century, analysis of large-scale social change (or macro comparative research), came to constitute the "modernization paradigm" that became orthodoxy across the post-World War II social sciences. The modernization paradigm was interdisciplinary and encompassed a broad range of social phenomena; two of its components were an evolutionary theory of large-scale social transformation (used to understand economic development) and a functionalist theory of the working of modern societies (which came to dominate mainstream sociology). Both of these components privileged the nation-state as the site within whose boundaries were contained all the fundamental processes needed to understand the phenomena being studied - be it the presence or absence of wealth, long-term changes in social inequality, or patterns of individual social mobility.

For understanding societal change, three fundamental assumptions of the modernization paradigm are of particular importance: 1) modernization is a long-term process of (ultimately progressive) social change that is "internal" (i.e., occurs within the nation-state); 2) this change represents a singular, overarching transition from traditional to modern; and 3) the transition brings homogeneity, as it ultimately results in growing convergence (of incomes, political institutions, systems of meritocracy, and the like). Likewise, it was generally assumed, if at times only implicitly, that modernization entailed the interdependent and simultaneous transformation of the economic (i.e., through industrialization and/or urbanization), the social (i.e., through the growing importance of achievement in shaping stratification), and the political (i.e., through democratization). In this sense, the modernization paradigm carried normative connotations: the process is "good" in that it entails the virtuous co-development of all three spheres of modern organization.

World-system analysis was born in the early 1970 s as a direct critique of the modernization paradigm. Not in professing to offer better theories of development or wiser industrialization policies, but as a transformative framework that would constitute a "fundamental protest" against the ways we think we know the world (Wallerstein 2004:xi). ${ }^{2}$ At the very heart of this "protest" was a panoptic reconceptualization of the relevant unit of analysis. World-systems analysts questioned the extent to which national histories, national economies, or national societies really existed. Modern social change, they argued, could not be understood using local, national, or even continental social science. The important questions can only be studied in the context of a historically conceived world-system:

If there is one thing that distinguishes a world-system perspective from any other, it is its insistence that the unit of analysis is a world-system defined in terms of economic processes and links, and not any units defined in terms of juridical,

\footnotetext{
${ }^{2}$ Wallerstein (2004:xi) continues the thought by noting that this mode of analysis is also a "reflection of, an expression of, the real protest about deep inequalities of the world-system are so politically central to our current times."
} 


\section{JOURNAL OF WORLD-SYSTEMS RESEARCH}

political, geographical, or other criteria. (Hopkins and Wallerstein, et al. 1982:72)

World-systems analysis is a fundamental reconceptualization of the whole relative to the whole's parts. Processes extend not only beyond nation-state boundaries, but often, irrespective of them. More importantly, these processes are seen as relational, so the parts may not be identified independently of their occurrence in the whole, and the whole cannot be reduced to each part. If in macro comparative research, the goal is to analyze the parts and maintain their additive ordering, in world-systems research the goal is to analyze how the whole is constantly being formed and reformed by relations between parts. ${ }^{3}$ As Hopkins (1982b:149) states it:

I think the methodological directive with which we work is that acting units or agencies can only be thought of as formed and continually reformed, by the relations between them. Perversely, we often think of the relations as only going between the end points, the units or the acting agencies, as if the latter made the relations instead of the relations making the units.

Thus, world-systems analysis can be seen as a theoretical movement that necessarily gave rise to methodological issues in virtue of the theoretical movement, and that for the most part center around the fundamental unit of analysis. ${ }^{4}$ Nation-states are seen as partial institutions of the whole, a singular world-economy. Since the world-economy in this framework is systemic and historical, it will remain the same over time while simultaneously changing from one moment to the next. Wallerstein (2004: 22) calls this a "paradox, but not a contradiction," and puts forward that the fundamental task of world-systems analysis is to successfully deal with this paradox.

It is in this sense that theory and method are one in the same: the world-systems perspective is not a unified "theory," it is a way of doing social science, an angle of vision. In the Hopkins/Wallerstein formulation, the whole is the capitalist world economy - a single integrated and expansionary system of production generating and reproducing inequality through the axial division of labor between core and peripheral zones. But scholars can conduct systemic analysis without necessarily assuming the all-encompassing world system. Wallerstein and Hopkins presume a "whole" that governs its "parts." But one can just as easily make comparisons by progressively constructing a whole by bringing in successive parts, in constant relations with themselves. McMichael (1990:386) calls this strategy "incorporated comparison" where the whole emerges as an historical configuration via comparative analysis of parts posited as "moments in a self-forming whole." In other words, a world-historical perspective means taking the world as whole as the relevant unit of analysis, a methodological program that need not necessarily coincide with the Wallerstein/Hopkins theoretical conceptualization of what this whole looks like.

${ }^{3}$ As Hopkins (1982a) explains The object of inquiry becomes sets of processes (that are abstract in contrast to the concrete whole), not conditions. For example, inequality is produced by relations among the acting units (nation-states), and is not a condition of them.

${ }^{4}$ In this sense, the "protest" that Wallerstein speaks is also the questioning of the methodological and epistemological assumptions of social science. 


\section{RETHINKING INEQUALITY FROM A WORLD-HISTORICAL PERSPECTIVE}

Today, the study of social inequality and mobility constitutes a highly fragmented area of inquiry, with very little dialogue between the many subfields of specialization - some focus on betweennation inequality, and others on within-nation, some employ data from a particular part of the world, and others from somewhere else, and so forth. As discussed above, "The Blind Men and the Elephant" metaphor is an apt description of existing studies of inequality and mobility that can be "partly in the right" in describing what they perceive. But they are "in the right" only within the particular boundaries of the sphere they choose to describe, and with the specific scopes (e.g., data, techniques, assumptions) through which observations are made. Hence, various "parts" are adequately described, but what is missing is an account of the whole.

Like other areas of inquiry in the social sciences, inequality and stratification have been conceived primarily as processes that occur within national boundaries. Such a focus has produced a number of influential overarching narratives. One such narrative is that the relative well-being of people is shaped most fundamentally by the capacity of home-grown institutions to promote economic growth and/or equity. Another, that people over time have become more stratified by their relative achievement and effort rather than by the characteristics with which they are born. A third one, a corollary of the other two, is that upward social mobility is fundamentally the outcome of the adoption of better domestic institutions by countries, and/or the acquisition of greater human capital by individuals.

A world-historical perspective calls these narratives into question. In a forthcoming book Unveiling Inequality: A World-Historical Perspective, we argue that such a perspective reveals key processes of inequality that are otherwise hidden from nation-state analysis (Korzeniewicz and Moran, Forthcoming). Such a perspective reveals that the institutional arrangements shaping inequality within- and between-countries have always been relational, that is simultaneously national and global. In particular, the development of relatively low levels of inequality seen within wealthy countries is directly related to the persistence of very high levels of inequality seen between countries: the former has been sustained through institutional arrangements that limited competitive pressures within wealthy countries, while simultaneously transferring these competitive pressures (and the inequality that goes with them) abroad.

So what appears to be the product of individual achievement and effort in wealthy countries has gone hand-in-hand with global constraints that accentuated and entrenched high levels of inequality between countries. Thus, just as ascribed criteria like race play a key role in forming high levels of inequality within-countries like Brazil and South Africa, such criteria continue to play a fundamental role in sustaining inequality at a global level as well. Over the last two centuries, nationality has become the crucial ascribed characteristic shaping the status of people within global stratification.

From a world-historical perspective, beyond the status that can be acquired by achievement within one's own country, the key determinant of one's relative position within a global system of stratification is the relative level of wealth of the country within which one is born. Thus, a much as markets have become "globalized" over recent decades, social stratification and mobility continue to revolve around institutional arrangements that unequally distribute resources on the basis of ascriptive categorical differences. The current uneven distribution of income and wealth in the world today would unlikely exist in the absence of the institutional arrangements that limit access to markets and political rights on the basis of national 


\section{JOURNAL OF WORLD-SYSTEMS RESEARCH}

borders. In this sense, while it is not the case that the populations of wealthy nations have attained their privileges by making much of the rest of the world poor, we contend that the relative privileges characterizing high-income nations historically required the existence of institutional arrangements ensuring the exclusion of the vast majority of others from access to opportunity.

Such insights are not apparent when focusing on inequality and stratification using nation-states as the unit of analysis. From such a standpoint, each nation is perceived to have wealthier and poorer populations, engaged in negotiation and/or conflict with one another over the distribution of resources, and institutions and political actions have the effect of either enhancing or reducing overall levels of inequality and social mobility. Outcomes appear as fairly clear, and limited to the national spaces within which institutions are assumed to operate, and the criteria used for the exclusion of non-national populations comes to be perceived as legitimate and natural (of course, even within a national population, deciding who should be included has been a contested terrain: for example, most social scientists in the United States focused on male workers and employers when thinking about relative levels of equity in the 1950s, but had to rethink the role of interactions between men and women after the 1960s).

In these accounts, our past, present and future are marked by the growing triumph of individual achievement over ascription as the crucial criteria shaping growing opportunity. Such might indeed be the patterns revealed when the field of vision is limited to discrete, "nationally bounded" "societies:" The actual patterns of inequality, stratification and mobility experienced by most people, as well as the persistence of ascriptive criteria as a basis of stratification, only become unveiled when the world as a whole is taken as the proper unit of analysis.

\section{CONCLUSION}

In the 1970s, the claims (and terminology) of world-systems scholars were seen as bold, radical, and, some argued even pernicious, interventions into the ways we conduct macro comparative research. Today, we live in a time where something called "globalization" has demonstrated the validity of the world-systems perspective, at least on its face. Does anyone other than politicians running for national office still take seriously an independent "national economy?" Or perhaps it is just that world-system terminology - "world-economy," "world-market," even "core and periphery" - has been semantically appropriated for common use? It is this latter scenario that Wallerstein warns of , that using the language "for other, indeed opposite purposes (than those of world-systems analysis)...can cause serious confusion in the general scholarly public, and even worse, may lead to confusion on our own part, thus undermining the tasks we have set for ourselves" (quoted in Arrighi 1999:121).

The importance of semantics surrounding the relevant unit of analysis thus takes two forms. On the one hand, it is important to recognize, and continue to distinguish between, different methodological frameworks used to conduct macro comparative social science. This involves above all, a careful theoretical determination of the relevant unit of analysis. But also can be reflected in the ways in which language is employed, especially in a time when worldsystems analysis - at least its terms and major concepts - are being acculturated across the social sciences. Thus, the title of an ASA panel originally called "Methodology for World-Systems Analysis" became a special-issue in this journal called "Methodological Issues in Macro Comparative Research.” 
On the other hand, debates surrounding the relevant unit of analysis have much broader implications. As Beck (2007:701) explains, taking the world as a whole as the relevant unit of analysis is not a simple project of learning about others, some sort of open-minded realization: "It is an integral part of our understanding of the reality of ourselves. It is a complex project of unthinking the ontological premises and dualisms of nation-state sociology - such as national and international, internal and external, citizen and alien, us and them." If we rethink the boundaries that contain the processes relevant to understanding sociological phenomena - that is, rethink the relevant unit of analysis - we can start to "see" things previously "hidden" by nation-state sociology. And this methodological shift directly leads to the rethinking of such boundaries for social action, social activism, and social justice.

Just as shifting the boundaries of the unit of analysis from the nation-state to the world as a whole forces us to reconsider the empirical processes that are relevant to understand existing inequality, the same shift in boundaries makes it incumbent upon us to redefine who is included in the relevant community when morally assessing social justice. Just as we might decide that race or gender should not be criteria limiting access to opportunity, from a world-historical perspective we might challenge the naturalization of national citizenship as a justification for categorical inequality. It becomes upon us to decide whether the life chances of people should be restricted by the blind luck of their place of birth.

\section{REFERENCES}

Arrighi, Giovanni. 1999. "Globalization and Historical Macrosociology." Pp 117-133 in Sociology for the Twenty-First Century, edited by Janet L. Abu-Lughod. Chicago: University of Chicago Press.

Bach, Robert L. 1982. "On the Holism of a World-System Perspective." in World-Systems Analysis: Theory and Methodology, edited by Terence K. Hopkins and Immanuel Wallerstein. Beverley Hills, CA: Sage.

Beck, Ulrich. 2007. "Beyond Class and Nation: Reframing Social Inequalities in a Globalizing World." British Journal of Sociology 58:679-705.

Hopkins, Terence K. 1982. "The Study of the Capitalist World-Economy: Some Introductory Considerations." in World-Systems Analysis: Theory and Methodology, edited by Terence K. Hopkins and Immanuel Wallerstein. Beverley Hills, CA: Sage.

. 1982b. "World-Systems Analysis: Methodological Issues." in World-Systems Analysis: Theory and Methodology, edited by Terence K. Hopkins and Immanuel Wallerstein. Beverley Hills, CA: Sage.

Hopkins, Terence, and Immanuel Wallerstein, et al. 1982. "Patterns of Development in the Modern World-System." in World-Systems Analysis: Theory and Methodology, edited by Terence K. Hopkins and Immanuel Wallerstein. Beverley Hills, CA: Sage.

Korzeniewicz, Roberto Patricio, and Timothy Patrick Moran. Forthcoming. Unveiling Inequality: A World-Historical Perspective. New York: Russell Sage Foundation.

McMichael, Philip. 1990. "Incorporating Comparison Within a World-Historical Perspective: An Alternative Comparative Method." American Sociological Review 55:385-397.

Wallerstein, Immanuel. 2004. World-Systems Analysis: An Introduction. Durham, NC: Duke University Press. 


\section{JOURNAL OF WORLD-SYSTEMS RESEARCH}

Weber, Max. 1996 [1905]. The Protestant Ethic and the Spirit of Capitalism. Los Angeles: Roxbury Publishing Company. 